\title{
Effects of Adoption of Rice Production Technologies on Farmers' Income in Borno State, Nigeria
}

\author{
${ }^{1}$ Ibrahim, A. A., ${ }^{2}$ Mustapha, S.B. and ${ }^{3}$ Nuhu, S. H. \\ ${ }^{1,2,3}$ Department of Agricultural Extension Services, University of, Maiduguri, Nigeria
}

\begin{abstract}
The study examined the effects of adoption of rice production technologies in Borno State, Nigeria. A stratified random sampling method was used to select 534 upland, lowland and Fadama rice farmers in the study area. Data were analyzed using both descriptive and inferential statistical tools. The descriptive tools include; frequencies, percentages, Means, and standard deviation. Inferential statistics such as multiple regression and correlation analysis were used to show the degree of relationship between variables. The study indicates that majority (62.2\%) of the respondents had adopted seed selection and had adoption score of 5.0.The results indicated that majority (71.90\%) of the respondent's harvested 40 bags/100kg and above. The result shows that seed selection coefficient $\left(3.098^{* *}\right)$, planting depth coefficient $\left(2.976^{* *}\right)$, irrigation system coefficient (3.530**), water management coefficient $\left(4.502^{* *}\right)$ and tube wells coefficient (3.671**), were positively significant to income from rice sales at $1 \%$ level of significance. The study recommended that improved awareness creation should be provided through extension services on rice production technologies supported with the provision of inputs including credit facilities in the study area.
\end{abstract}

Key words: Adoption, Effects, Rice technologies, Farmers income, Nigeria

\section{Introduction}

Through attaining self reliance in food production and thus achieving a concrete food security, a country like Nigeria can move toward its ultimate goal of economic development. Nevertheless, in the context of high population growth, intensive food supply through rice production is one of the solutions to food security in Nigeria. The main objective of the Government's agricultural policy in Nigeria emphasized on increasing food supplies for the teaming population as well as providing income generating sources for rural people. As there has not a single unit of productive arable land left, in order to achieve those national goals we have to adopt some modern advanced technologies to boost up the present agricultural output. This may be carried out through increased cropping intensity, providing appropriate time oriented irrigation facilities, wide spread incorporation of modern high yielding varieties [1]., [9], applying the judicial and efficient doses of organic and balanced synthetic fertilizers [3]., [6].

The success of any technology depends on its dissemination among the potential users, which ultimately is measured by the level of adoption of that technology [5].,[8]. It is assumed that notable improvements can take place in Nigerian agriculture, if the available technologies were accepted and adopted by the farmers. For this reason, this study was conducted to gain an understanding on the effects of adoption of rice production technologies by the farmers.

\section{Objectives of the study}

The main objective of the study was to examine the effects of adoption of rice production technologies in Borno State, Nigeria. The specific objectives were:

I. determine the level of adoption of rice production technologies among respondents;

II. assess the level of output of rice by respondents in the study area; and

III. Examine the effects of rice production technologies on income of respondents in the study area.

\section{The Study area}

\section{Methodology}

The study was carried out in Borno State which lies between longitudes $11^{\circ} 05$ and $11^{\circ} 45^{1}$ and latitudes $09^{\circ} 10$ and $14^{\circ} 20$ [2]. The state has the largest land mass among the states in the Federation. It is bordered internationally by Cameroon to the East, Niger to the North and Chad to the Northeast. Borno state shares internal borders with Adamawa State to the South, Bauchi to the Southeast and Yobe to the West [4]. According to the [7], the State has a population of 4, 151, 193 million people with an annual growth rate of about 3.2 percent. The state has a mean annual rainfall of $250 \mathrm{~mm}$ in the extreme North and a maximum of $1000 \mathrm{~mm}$ in the South. The State has a tropical climate marked by alternating dry and rainy seasons, and the average temperature is $38.6^{\circ} \mathrm{C}[2]$. 


\section{Sampling Procedure and Sample Size}

Sampling for administering questionnaires was done using the three Agricultural zones. Thus, three (3) Local Government Areas (LGAs) were randomly selected from each of the three zones giving a total of nine (9) LGAs namely; Dikwa, Marte, Mobbar, Jere, Konduga, Bama, Bayo, Askira-Uba and Shani for the study. Three (3) rice producing villages were randomly selected from each of the nine (9) LGAs, bringing a total of 27 villages from all the three zones.

A stratified random sampling method was used to select the upland, lowland and Fadama rice farmers in the study area. Due to the heterogonous nature of the rice producing farmers in the state, the respondents were divided into three stratified into three sub-groups. The first stratum (sub-group) consists of farmers whose activity was primarily upland rice farming, the second stratum (sub-group) consists of producers from lowland areas and the third stratum (sub-group) was the Fadama rice farmers. The BOSADP provided the sampling frame for the proportionate selection of the respondents in each stratum bringing a total of 534 rice farmers used in the study.

Data were analyzed using both descriptive and inferential statistical tools. The descriptive tools include; frequencies (f), percentages (\%), Means $(\pi)$, and standard deviation (sd). Inferential statistics such as linear multiple regression and correlation analysis were used to show the degree of relationship between variables.

\section{Level of Adoption of Rice Technologies by Farmers}

\section{Results And Discussion}

Table 1 shows the adoption score and level for 13 rice production technologies promoted by BOSADP which were considered for the purpose of classifying respondents into their respective adoption level. Availability of suitable arable land and technologies for rice production are pre-requisite for rapid agricultural development. The issue of agricultural technology adoption by rice farmers had generated an increasing interest in the face of national economy Worldwide, this is because the decision to adopt or reject rice production technologies are basically related to various levels of stages within the farmer himself, however in this study area rice farmers opinion on the stages of their adoption levels of rice technologies were presented in Table 1.

Table 1: Score and Level of Adoption by Respondents for Rice Production Technologies

\begin{tabular}{|lcccc|}
\hline $\begin{array}{l}\text { Rice production } \\
\text { Technologies }\end{array}$ & $\begin{array}{c}\text { No. of } \\
\text { Adopters (f) }\end{array}$ & $\begin{array}{c}\text { Percentage of } \\
\text { Adopters (f) }\end{array}$ & $\begin{array}{c}\text { Adoption } \\
\text { Score }\end{array}$ & $\begin{array}{c}\text { Adoption } \\
\text { Level }\end{array}$ \\
Seed selection & $332^{\mathrm{H}}$ & 62.2 & 5.01 & High \\
Planting depth & $301^{\mathrm{H}}$ & 56.0 & 4.85 & High \\
Plant spacing & $299^{\mathrm{H}}$ & 56.0 & 4.85 & High \\
Pesticide application & $291^{\mathrm{H}}$ & 54.4 & 4.79 & High \\
Seed variety & $287^{\mathrm{H}}$ & 53.7 & 4.76 & High \\
Land preparation & $282^{\mathrm{H}}$ & 52.8 & 4.74 & High \\
Herbicide application & $278^{\mathrm{H}}$ & 52.1 & 4.71 & High \\
Fertilizer application & $261^{\mathrm{H}}$ & 48.9 & 4.61 & High \\
Use of combined harvester & $258^{\mathrm{H}}$ & 48.3 & 4.60 & High \\
Table well & $242^{\mathrm{M}}$ & 45.3 & 4.50 & Medium \\
Modern Storage system & $241^{\mathrm{M}}$ & 45.1 & 4.49 & Medium \\
Water management & $222^{\mathrm{L}}$ & 41.6 & 4.37 & Low \\
Irrigation system & $38^{\mathrm{L}}$ & 7.10 & 2.38 & Low \\
Total & \multicolumn{5}{c}{ Adoption Score } & $\mathbf{5 8 . 6 4}$ \\
Mean & \multicolumn{5}{c}{ Score Values } \\
\hline
\end{tabular}

Computed from field survey; 2010

High = H, Medium = M, Level $=\mathbf{L}$

Table 1 indicates that majority $(62.2 \%)$ of the respondents adopted seed selection and has adoption score of 5.0. This means that majority $(60.2 \%)$ of the respondents who adopted seed selection were classified as high adopters. This was followed by those respondents $(56.4 \%)$ who adopted planting depth had 4.85 adoption score classified as high adopters. Respondents (56.0\%) who adopted plant spacing whose adoption score were 4.83 were classified as high adopters. Those respondents $(54.4 \%)$ adopted pesticide application for the control of rice pest had adoption score of 4.78 and were considered as high adopters. Those respondents who adopted seed varieties had adoption score of 4.7 and were classified as high adopters. It is a common knowledge that various types of weed were associated with rice crops and herbicide application with the adoption score of 4.71 which were classified as high adopters. This was followed by those respondents $(48.9 \%)$ that adopted fertilizer 
applications had adoption score of 4.61 and are classified as high adopters. Respondents (48.3\%) had adopted combined harvesters as their rice production technologies with adoption score of 4.60 which was regarded as high adopters.

It is evident from these findings that $45.3 \%$ of the respondents have adoption those score of 4.50 classified as medium adopters and $45.1 \%$ of the respondents adopted modern storage system with 4.49 adopted modern water management system with the adoption score of 4.37 considered as low adopters. Only $7.10 \%$ of the respondents had adopted modern irrigation system with adoption score of 2.38 classified as low adopters.

Generally, nine out of the 13 rice production technologies promoted by BOSADP had been classified under high adopters while two of the rice technologies were considered as medium adopters. The rest (2) of the technologies promoted by BOSADP fell under low adopters suggesting that respondents rated BOSADP performance high in terms of technology transfer.

\section{Rice Production Output among Respondents}

On respondent's level of rice production, they were asked to indicate their output of rice production as of last year cropping season and their responses were presented in Table 2 . The results indicated that most of the respondents $(28.1 \%$ ) harvested 40 bags of $100 \mathrm{~kg}$ per bag. About $36.7 \%$ of the respondents reported 41 to 80 bags of $100 \mathrm{~kg}$ of rice yield in the last cropping season. Only $15.5 \%$ of the respondents claimed that they harvested up to 120 bags of rice of $100 \mathrm{~kg}$. About $12.0 \%$ of the respondents harvested between 121 to 160 bags of rice at $100 \mathrm{~kg}$ per bag, while $7.7 \%$ of the respondent harvested up to 161 bags of rice $100 \mathrm{~kg} / \mathrm{bags}$.

There are two most common potions to increase the level of rice production. The first is through expansion of farm land area to accommodate more crop population per unit (ha) area of farm land. The other one is adoption of rice varieties and other production technologies. The combination of land expansion and adoption of rice technologies were also used to increase the level of rice production by farmers in order to increase rice technologies were also used to increase the level of rice production by farmers in order to increase rice production in the study area. BOSADP had embarked on an accelerated adoption of rice varieties and other production technologies.

Table 2: Production Output of Rice by Respondents (in $\mathrm{Kg} / \mathrm{Bag})(\mathrm{n}=534)$

\begin{tabular}{lcc}
\hline $\begin{array}{l}\text { Rice Production Output } \\
\text { (in 100kg/bag) }\end{array}$ & $\begin{array}{c}\text { Frequency } \\
\text { (f) }\end{array}$ & $\begin{array}{c}\text { Percentage } \\
(\mathbf{\%})\end{array}$ \\
\hline $0-40$ & 156 & $(28.1)$ \\
$41-80$ & 196 & $(36.7)$ \\
$81-120$ & 83 & $(15.5)$ \\
$121-160$ & 64 & $(12.0)$ \\
Above 161 & 41 & $(7.7)$ \\
\hline Total (N) & $\mathbf{5 3 4}$ & $\mathbf{1 0 0}$ \\
\hline
\end{tabular}

Source; Field survey, 2010

This finding shows that $64.8 \%$ of the respondents harvested below 80 bags at $100 \mathrm{~kg}$ per bag which does not seem to be commensurate with the BOSADP aims of boasting rice production in their operational area despite the various extension agents assigned to farmers over the years.

\section{The Influence of Rice Production Technologies on Income of Respondents}

Table 3 points out that seed selection coefficient $\left(3.098^{* *}\right)$, planting depth coefficient $\left(2.976^{* *}\right)$, irrigation system coefficient $(3.530 * *)$, water management coefficient $(4.502 * *)$ and tube wells coefficient $\left(3.671^{* *}\right)$, were positively significant to income from rice sales at $5 \%$ level of significance. This means that increase in seed selection for rice farming leads to increased production and subsequent income from rice sales. 
Table 3: Relationship between Rice Production Technologies and Income Level

\begin{tabular}{llllll}
\hline Model & Beta in & $\begin{array}{l}\text { Regression } \\
\text { Coefficient (t-value) }\end{array}$ & $\begin{array}{l}\text { Significant } \\
\text { level }\end{array}$ & $\begin{array}{l}\text { Partial } \\
\text { correlation }\end{array}$ \\
\hline Seed selection & .139 & $3.098^{* *}$ & .002 & .133 & Decision \\
Land preparation & .110 & 2.602 & .040 & .089 & $\mathrm{~S}$ \\
Planting depth & .125 & $2.976^{* *}$ & .003 & .128 & $\mathrm{NS}$ \\
Herbicide application & .081 & -1.535 & .125 & -.066 & $\mathrm{~S}$ \\
Application of pesticide & .029 & .518 & .604 & .022 & $\mathrm{NS}$ \\
Irrigation system & .184 & $3.502^{* *}$ & .000 & .151 & $\mathrm{NS}$ \\
Modern storage system & .072 & 1.746 & .081 & .076 & $\mathrm{~S}$ \\
Water management & .188 & $4.502^{* *}$ & .000 & .192 & $\mathrm{NS}$ \\
Tubes wells & .171 & $4.153^{* *}$ & .000 & .177 & $\mathrm{~S}$ \\
Wash bores & .512 & $3.671^{* *}$ & .000 & .157 & $\mathrm{~S}$ \\
Modern harvester & .101 & 2.447 & .015 & .106 & $\mathrm{~S}$ \\
\hline
\end{tabular}

\author{
Source: Field Survey Data, 201. \\ Key \\ Significant at $5 \%$ level $=\mathrm{S}$ \\ Not Significant $=$ NS
}

This means that increase in seed selection for rice farming leads to increased income from rice sales. This could be related to increase in the rice yield from the selected rice varieties which leads to increase in rice production for marketing and hence increase in income of the respondents. Similarly, irrigation system, water management and tube well, showed a positive significant relationship to income levels at $5 \%$ level of significance. This indicates that an increase in the adoption of modern irrigation system (i.e increase in water management and increase in tube wells) leads to an increase in yield and hence increases income from rice sales.

Similarly, herbicide application and income from rice sales had a negative significant relationship $\left(2.599^{* *}\right)$ at $10 \%$ level of as significance. This could be attributed to the fact that increase in herbicides application leads to decrease in income level of the farmers because of high cost incurred in the purchase of herbicides.

\title{
IV. Conclusion
}

The study revealed that majority of the respondents adopted seed selection and had harvested more than $40 \mathrm{bags} / 100 \mathrm{~kg}$ of rice in the study area. The results equally indicated that the rice production technologies adopted by respondents had significantly increased their level of income.

\section{Recommendations}

Based on the findings of the study, the following recommendations were made:

1. Government should provide irrigation systems strengthened with extension services on water management techniques in the study area.

2. Improved awareness creation on rice production technologies should be provided through extension services supported by provision of inputs including credit facilities.

3. Formation of cooperative societies should be encouraged. This could avail government and non governmental organizations" support through the provision of input services such as credit facilities in the study area.

\section{References}

[1] Agbamu, J. U. (2006): Borno State Ministry of Agriculture, Annual Report,Produce Division Maiduguri, Nigeria.

[2] BOSADP (2003). Borno State Agricultural Development programme (BOSADP). Annual Report, B omo State of Nigeria.

[3] Bzugu, P. M. (2002): Factors Influencing Adoption of Farm Technological Innovations among Cereal Crop Farmers in Adamawa State, Nigeria. Unpublished PhD Thesis, Agricultural Extension and Rural Sociology, University of Maiduguri, Nigeria.

[4] Daura, M.M. (2001). The physical environment and development: A study of Borno region in environment and development issues in Sub - Sahara Africa. Seminar Series, vol.1. Faculty of Social and Management Sciences, University of Maiduguri, Nigeria, PP34 47.

[5] Iheanacho, A. C. (2006): Economics of Millet Production under Different CroppingSystems in Borno State of Nigeria, Unpublished Ph.D Thesis submitted to the Department of Agricultural Economics and Rural Sociology. A.B.U. Zaria

[6] Mohammed, I. and Mokiri, S. A. (1992): The Agricultural Supply Companies under the Agricultural Development Projects: An Appraisal of FASCO in Sokoto State, Nigeria.

[7] National Population Commission (2006): National Census Report, National Population Commission, Abuja, Nigeria.

[8] Ogunwale, A. B; Ayoade, A. R, and Ayansina, S. O. (2006): Extension Service of Farmers' Production Activities in Ogbomoso Agricultural Zone of Oyo State. Nigeria, Journal of Agricultural Extension, Vol. 9 Pp 150 - 155.

[9] Tologbonse, E. B; Alabi M. O. and Tergama, A. (2005); Adoption of Recommended Crop Protection Practices by Sesame Farmers in Benue State, Nigeria. Journal of Agricultural Extension of Nigeria, A Publication of AESON, Vol. 8 Pp 106. 